\title{
A Grammatica Philosophica da Lingua Portugueza de Jerónimo Soares Barbosa: contributos para o estudo da grafia no século XIX Jerónimo Soares Barbosa's Grammatica Philosophica da Lingua Portugueza: contributions to the study of the orthography in the nineteenth century
}

RESUMO: Jerónimo Soares Barbosa é autor daquela que é, ainda hoje, por muitos considerada uma das melhores gramáticas da língua portuguesa: a Grammatica Philosophica da Lingua Portugueza (1822). Esta gramática conheceu durante o século XIX sete edições $(1822,1830,1862,1866$, $1871,1875,1881)$, todas elas publicadas sob a chancela da Academia das Ciências de Lisboa. Tendo por base o cotejo destas edições oitocentistas, propomo-nos analisar a estrutura gráfica de cada um dos textos, destacando os aspetos que refletem a evolução da grafia na centúria oitocentista.

PALAVRAS-CHAVE: Historiografia Linguística. Grammatica Philosophica da Lingua Portugueza. Ortografia portuguesa. Edição de texto.
ABSTRACT: Jerónimo Soares Barbosa is the author of what is still today considered by many one of the best grammars of the Portuguese language: the Grammatica Philosophica da Lingua Portugueza (1822). Throughout the nineteenth century, this work had seven editions $(1822,1830,1862,1866$, 1871, 1875, 1881), all published by the Academia das Ciências de Lisboa. Based on the comparison of these nineteenth-century editions, we aim to analyze the graphic structure of each of the texts, highlighting the aspects that reflect the evolution of the orthography during the nineteenth century.

KEYWORDS: Historiography of Linguistics. Grammatica Philosophica da Lingua Por.ugueza. Portuguese orthography. Text edition.

\section{Introdução}

Filho de Manuel Freire de S. Lázaro e de Violante Rosa Soares, Jerónimo Soares Barbosa nasceu em Ansião, em finais de janeiro de $1737,{ }^{1}$ e faleceu a 5 de janeiro de 1816, em São João de Almedina, Coimbra. ${ }^{2}$ Tendo sido educado no seminário episcopal de Coimbra, aí foi ordenado presbítero em 1762.

\footnotetext{
* Doutora em Historiografia Linguística. Professora Auxiliar na Universidade de Trás-os-Montes e Alto Douro Vila Real - Portugal.

${ }^{1}$ Rodrigues de Gusmão (cf. 1857, p. 260) e Inocêncio (cf. SILVA, 1859, III, p. 276) estabelecem, como data de nascimento, 24 de janeiro de 1737. Rolf Kemmler (cf. KEMMLER, 2012b, p. 102) constata que o assento de batismo do gramático não indica nenhuma data de nascimento, mas apenas que foi batizado no dia 2 de fevereiro de 1737. No entanto, o investigador conclui que, "dado que o padrinho e tio materno era também o pároco da vila e freguesia de Ansião, não estranha que este terá procedido logo ao batismo do afilhado, pelo que julgamos ser possível que tenha mesmo nascido no dia 24 de janeiro de 1737, apesar de esta data não se encontrar referida em qualquer documentação contemporânea" (KEMMLER, 2012b, p. 102).

${ }^{2}$ Para a transcrição dos assentos de batismo e óbito de Jerónimo Soares Barbosa, consulte-se Kemmler (2012b, p. 102).
} 
No ano de 1766, “após a saída do professor régio Manuel Francisco da Silva Veiga, provido numa beca da Relação do Rio de Janeiro, e tendo-se tornado obrigatória a frequência da Retórica para os candidatos à Universidade [...]” (AZEVEDO, 2012, p. 30), passou a professar Retórica e Poética no Colégio das Artes de Coimbra e, dois anos depois, em 1768, formou-se em Cânones.

A 8 de julho de 1792 foi "nomeado visitador das escholas de primeiras letras, e da lingua latina na provedoria de Coimbra [...]" (GUSMÃO, 1857, p. 260) e, no ano seguinte, em 1793, foi encarregue de promover e dirigir as edições dos autores clássicos para uso das escolas. Posteriormente, em 1800, foi nomeado deputado da Junta da Diretoria Geral dos Estudos, sendo já, por esta altura, professor jubilado da cadeira de Retórica e Poética.

Em 1789 tornou-se sócio correspondente da Academia das Ciências de Lisboa, agradecendo a eleição por carta datada de 17 de abril do mesmo ano. Em 1803, é promovido a sócio livre.

Trata-se de "[...] um homem de verdadeiro merito, que dava e sabía o por que das cousas" (LEAL, 1859, p. 3) e de um ilustre humanista, que prestou um importante serviço às "letras, e ao progresso e aperfeiçoamento dos estudos em Portugal” (SILVA, 1859, III, p. 276).

Tendo dedicado grande parte da sua vida ao ensino, Jerónimo Soares Barbosa empenhouse na renovação dos métodos pedagógicos de então, consubstanciando as suas propostas em obras de elevado mérito. Do seu labor gramatical, destaca-se a Grammatica Philosophica da Lingua Portugueza, ou principios da grammatica geral applicados á nossa linguagem, obra póstuma, publicada em 1822 pela Academia das Ciências. Esta gramática, por muitos ainda hoje considerada uma das melhores da Língua Portuguesa, contou, no século XIX, com sete edições $(1822,1830,1862,1866,1871,1875,1881)^{3}$ e só voltaria a ser reeditada em 2004, numa edição fac-similada da $1^{\mathrm{a}}$ edição por Amadeu Torres.

\section{As ideias ortográficas de Jerónimo Soares Barbosa e a grafia nas edições}

A realização da edição crítica da Grammatica Philosophica da Lingua Portugueza permitiu-nos perceber que existiam diferentes opções gráficas para a mesma palavra nos textos das sete edições ou até dentro do mesmo texto, levando-nos a questionar quais as principais

\footnotetext{
${ }^{3}$ Ao longo do presente artigo, estas edições serão designadas através das seguintes siglas: $1^{\text {a }}$ edição de 1822 edição $A ; 2^{\mathrm{a}}$ edição de 1830 - edição $B ; 3^{\mathrm{a}}$ edição de 1862 - edição $C ; 4^{\mathrm{a}}$ edição de 1866 - edição $D ; 5^{\mathrm{a}}$ edição de 1871 - edição $E ; \sigma^{\mathrm{a}}$ edição de 1875 - edição $F ; \sigma^{\mathrm{a}}$ edição de 1830 - edição $G$.
} 
diferenças gráficas e em que edições se situam e se os princípios propostos pelo autor estariam a ser aplicados nos textos impressos.

Com o intuito de responder a estas questões, encetamos um estudo que nos permitiu confrontar as ideias ortográficas do autor com a grafia constante nas edições. Neste sentido, seguidamente, apresentamos os dados obtidos acerca do uso do $<\mathrm{h}>$ e do apóstrofo, procurando confrontar a exposição das ideias do gramático acerca destes aspetos e a verificação da sua aplicação nas edições. Porque um autor é produto da sua época, à medida que vai sendo discutido o ideário do gramático, este será cotejado com as propostas de outros autores, sobretudo ortógrafos, destacando-se, para o século XVIII, João de Morais Madureira Feijó, ${ }^{4}$ autor daquele que “[...] chegou a ser o tratado ortográfico com o maior êxito, até inclusive no século XIX” (KEMMLER, 2001, p. 206), e Luís Caetano de Lima, autor da ortografia escolhida pela Real Academia de História, da qual o Padre Lima foi sócio fundador, “[...] para que se uniformizasse a ortografia das publicações da agremiação [...]” (GONÇALVES, 2003, p. 27). No século XIX, destacam-se os ortógrafos Tristão da Cunha Portugal, por ter escrito uma Orthographia, cujo sistema é "rectificado pelos princípios da Grammatica Philosophica da Lingoa Portugueza de Jeronimo Soares Barbosa" (PORTUGAL, 1856, p. III), e Carlos Augusto de Figueiredo Vieira, cujo Ensaio sobre a Orthographia Portugueza foi publicado pela primeira vez em 1844 e reeditado em 1859, portanto numa época próxima à impressão da terceira e quarta edições da Grammatica Philosophica.

\subsection{Definição de ortografia}

Na Grammatica Philosophica, Soares Barbosa estabelece a seguinte definição de ortografia:

A Orthographia he a Arte de escrever certo, isto he, de representar exactamente aos olhos por meio dos caracteres Litteraes do Alphabeto Nacional, os sons, nem mais nem menos, de qualquer vocabulo, e na mesma ordem, com que se pronuncião no uso vivo da Lingua: ou bem assim os que o mesmo vocabulo em outro tempo teve nas Linguas mortas, donde o houvemos.

Assim o vocabulo Ortografia, escripto por este modo, representa ao justo os sons de sua pronunciação viva na Lingua Portugueza. Porêm escripto, como se vê ao principio, representa, não so os sons, que tem presentemente, mas tambem os que teve em outro tempo no uso vivo da Lingua Grega, donde o houvemos (BARBOSA, 1822, p. 56).

\footnotetext{
${ }^{4}$ Neste trabalho, cita-se a $3^{\mathrm{a}}$ edição, de 1781 , por se tratar da primeira edição póstuma, a partir da qual se registaram as principais alterações.
} 
Esta definição, que retoma em quase tudo a apresentada pelo autor na Eschola Popular, ${ }^{5}$ remete-nos de imediato para dois tipos de sistemas ortográficos que durante as centúrias setecentista e oitocentista foram amplamente discutidos: o primeiro sistema, tendo como base o princípio fonético, propunha a representação das palavras tal qual se pronunciavam; o segundo, que dava primazia à componente etimológica, pretendia plasmar na grafia os étimos que estavam na origem das palavras. Soares Barbosa ilustra precisamente estes dois tipos de sistema recorrendo à palavra 'ortografia', que, dependendo da forma como se escreve, pode representar apenas o modo como se pronuncia ou a sua origem grega.

$\mathrm{O}$ autor prossegue, dizendo que:

A primeira Orthographia chama-se da Pronunciação; porque não emprega caracteres alguns ociosos e sem valor: mas tão somente os que correspondem aos sons vivos da Lingua. A segunda chama-se Etymologica, ou de Dirivação; porque admitte letras, que presentemente não tem outro prestimo senão para mostrar a origem das palavras (ibid., p. 56-57).

Durante os séculos XVII e XVIII, destacam-se como defensores de uma grafia de pendor fonético o ortógrafo João Franco Barreto e o eclesiástico Luís António Verney, que defendiam que as palavras se deviam escrever “[ [...] cõ as letras devidas, \& sómẽte necessarias, sẽ por uma por outra, nẽ alguma de mays, ou de menos [...]" (BARRETO, 1671, p. 1). Portanto, os portugueses “[...] devem escrever a sua lingua, da-mesma sorte que a-pronunciam” (VERNEY, 1746, p. 14).

A representar a proposta de uma ortografia etimológica está Madureira Feijó, que define ortografia como a

[...] Arte, que ensina a escrever com acerto nas letras, de que se compõem as dicçoens; na divisaõ, que se faz das palavras, quando naõ cabem inteiras no fim das regras; nos pontos e virgulas, com que se divide o sentido das oraçoens; nos accentos, ou tons, com que se pronunciaõ as vogaes em cada palavra (FEIJÓ, 1781, p. 7).

\footnotetext{
${ }^{5} \mathrm{Na}$ terceira parte da Eschola popular, Da calligraphia, e orthographia, ou arte de escrever bem e certo a lingua portugueza, pode ler-se a seguinte definição de ortografia:

ORTHOGRAPHIA he a Arte de escrever certo, isto he, de representar exactamente aos olhos por meio dos caracteres litteraes do Alphabeto Nacional os sons nem mais nem menos de qualquer vocabulo, e na mesma ordem, em que se pronuncião no uso vivo da lingua; ou bem assim os que o mesmo vocabulo em outro tempo teve nas linguas mortas, donde nos veio. Assim o vocabulo Ortografia, escripto deste modo, representa ao justo os sons da sua pronunciação viva na Lingua Portugueza. Porem escripto como se vê ao principio, representa não só os sons que tem, mas tambem os que teve em outro tempo no uso vivo da Lingua Grega, donde o houvemos (BARBOSA, 1796c, p. 56).

Acerca da comparação entre estas duas definições, consulte-se Kemmler (2012a).
} 
Note-se aqui o recurso a conceitos como "Arte" e "acerto", que nos remetem para a ortografia "[...] como aplicação de conhecimentos e enunciação de regras para a prática correcta da escrita" (GONÇALVES, 1992, p. 49).

A par destes dois sistemas ortográficos, muitas vezes contraditórios, caminhava um sistema misto, que conciliava etimologia e pronúncia, tendo por base o uso:

Entre estas duas Orthographias caminha a usual, assim chamada, porque não tem outra auctoridade se não a do uso presente e dominante; ja para seguir as Etymologias, e introduzir arbitrariamente escripturas mui alheas da pronunciação presente; ja para não fazer caso da dirivação mesma, e incoherente em seus procedimentos escrever, por ex: $\mathrm{He}, \mathrm{Huma}$ com $\mathrm{H}$, que não ha na origem Latina; e Filosofia, e Fyzica com F e Z, que não ha nas palavras Gregas (BARBOSA, op. cit., p. 57).

Destaque-se aqui a posição pioneira de Soares Barbosa em/reconhecer formalmente a ortografia usual como uma das três possíveis realizações. Na opinião de Kemmler (2012a, p. 314), “[...] é precisamente esta introdução formal do sistema misto, que oscila entre os dois sistemas 'clássicos' da teoria ortográfica, que deve ser considerada uma das maiores inovações da Grammatica philosophica em matéria ortográfica”.

Após a apresentação dos três sistemas ortográficos, o gramático reflete sobre o acesso da população a cada um deles. Considera que ao alcance do Povo illitterato só está a ortografia da pronunciação, uma vez que para escrever segundo este sistema não é necessário conhecer o funcionamento das línguas grega e latina, bastando apenas distinguir bem os sons de cada palavra:

Ja se vê que as Orthographias, Etymologica e Usual estão totalmente fóra do alcance do Povo illitterato. Porque nenhuma regra segura se lhe póde dar, ou elle perceber para deixar de errar a cada passo, que não seja a de largar a penna a qualquer palavra, que queira escrever, para consultar o vocabulario da Lingua.

Porêm a Orthographia da Pronunciação não he assim. Rectificada que seja esta; não tem elle mais do que distinguir os sons, quer simples, quer compostos, de que consta qualquer palavra, e figural-os com os caracteres proprios, que os Alphabetos Nacionaes para isso lhe dão (BARBOSA, op. cit., p. 57).

Se, por um lado, esta modalidade é a mais acessível àqueles que não têm conhecimentos acerca das línguas clássicas, por outro, 
ou por facil, ou por estranha ao uso presente da Nação, ${ }^{6}$ não he do gosto dos homens Litteratos, que não tendo a mesma difficuldade que tem os idiotas, para escreverem segundo as Etymologias, julgarião ter perdido seus estudos, se por isto se não distinguissem do vulgo imperito (ibid., p. 57).

Após considerar as vantagens e desvantagens inerentes a cada sistema, Soares Barbosa, numa atitude conciliatória, propõe-se apresentar as regras que caracterizam cada uma das ortografias. Assim, dedica os capítulos II e III às Regras proprias da Orthographia Etymologica, e Usual e às Regras proprias da Orthographia da Pronunciação, respetivamente. Note-se que no capítulo dedicado à ortografia da pronunciação, à semelhança do que já fizera na Eschola Popular, no artigo relativo à pontuação, Barbosa adota a escrita da pronunciação, facilitando assim o acesso e a compreensão das regras que está a explanar.

\section{$2.2 \mathrm{O}$ uso do $<\mathrm{h}>$}

No alfabeto do uso apresentado por Soares Barbosa, não se encontra este grafema. É só quando o gramático apresenta o abecedário vulgar ou tipográfico que ele surge, no entanto o autor aponta-o como uma letra sobeja, "[...] que, ainda sendo signal de aspiração, não deve ter lugar entre as Consoantes, mas sim entre os Accentos Prosodicos, aonde pertence” (ibid., p. 59). Ora, como se pode constatar, mantém-se aqui a tradição de atribuir ao $<\mathrm{h}>$ uma função de aspiração.

Efetivamente, no capítulo dedicado às modificações prosódicas, o gramático, para além de indicar os acentos agudo, grave e circunflexo, acrescenta um quarto acento, que corresponde ao espírito áspero dos gregos:

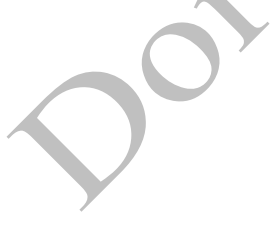

Alêm destes tres Accentos ha outro de Aspiração, que os Gregos notavão ao principio com dois $\mathrm{E}$ 约 virados hum para outro, ou unidos deste modo $\mathrm{H}$, e depois com a figura de huma virgula ás avessas, lançada por cima da vogal; e os Romanos com o primitivo $\mathrm{H}$ dos Gregos, posto na mesma linha antes da vogal aspirada (ibid., p. 41).

Comparando a língua portuguesa com a castelhana, no caso específico da nossa língua, o autor reconhece que a aspiração é quase inexistente, verificando-se apenas nas interjeições, pois estas palavras caracterizam-se por exprimirem as paixões da alma e, como tal, são as únicas que registam esta marca própria dos gregos:

\footnotetext{
${ }^{6}$ Através destas palavras, fica claro que a ortografia da pronunciação era um modelo 'estranho' à prática da nação, o que nos permite concluir que as várias propostas de implementação deste sistema não surtiram os efeitos desejados.
} 
A Lingua Portugueza differença-se muito nesta parte da Lingua Castelhana, que he abundantissima de aspirações, e por isso se faz algum tanto aspera e fatigante. A nossa não usa dellas se não nas Interjeições, em que são mui proprias para exprimirem o desafogo das paixões, pronunciando com ellas, e escrevendo ás vezes $a h ! o h ! h u i ! \& c$. (ibid., p. 41).

$\mathrm{Na}$ sequência das apreciações acerca da função do $<\mathrm{h}>$ enquanto sinal de aspiração, Soares Barbosa tece algumas considerações sobre o uso que na nossa língua se conferia a este grafema, evidenciando ainda as seguintes funções: integrar os dígrafos portugueses $<\mathrm{ch}$, lh, $\mathrm{nh}>$, indicar a etimologia das palavras e servir como sinal distintivo. Leiam-se as palavras do autor:

Usa porêm frequentemente do $\mathrm{H}$ para outros fins; ja para figurar algumas Consonancias suas proprias, que os Romanos não tinhão, quaes são as Prolações $\mathrm{CH}, \mathrm{LH}, \mathrm{NH}$; ja para conservar as etymologias Gregas e Latinas, como em Hypothese, Homem; ja para distinguir os sons semelhantes, como há verbo de $a$ preposição, hi adverbio de $i$ vogal, e hum nome de um vogal nasal (ibid., p. 41).

Com efeito, aqui revela-se, mais uma vez, o papel do gramático enquanto observador e descritor dos usos da língua. Consideremos, agora, as suas propostas para o uso do $<\mathrm{h}>$.

Já se disse que este grafema é, para o autor, um acento prosódico que serve para marcar a aspiração e, como o próprio refere, como no português poucas palavras são aspiradas, conserva-se este sinal apenas nas interjeições: "Nas Interjeições $a h$ ! oh! hui! ha a razão de serem estas vozes naturalmente aspiradas; para o que he muito proprio o H” (ibid., p. 71).

Nos textos das edições, estas palavras interjectivas surgem sempre com $<\mathrm{h}>$, tal como acontece ainda hoje com algumas delas: ah!, hai!, oh!, ah! ah!, hui!.

Sendo o $<\mathrm{h}>$ um carater latino, Soares Barbosa considera que ele deve figurar nas palavras que em latim o continham, de modo a evidenciar a sua etimologia:

Ainda que o H não tenha valor algum entre nós fóra talvez das Interjeições, comtudo deve-se conservar na escriptura das palavras, dirivadas do Latim para mostrarem a sua origem e com ella sua significação primitiva. Pelo que devemos escrever com elle Habil, Habitar, Habito, Haver, Herdar, Historia, Hombro, Honesto, Honra, Horror, Hospede, Homem, Humor, Hora, e outros semelhantes (ibid., p. 71).

Para além das palavras já registadas na citação, nas edições, encontra-se este $<\mathrm{h}>$ etimológico, em contexto inicial, também nas palavras hoje, homicidas, homologas, honestidade, horizontaes. 
Uma nota de destaque vai para a ocorrência do $<\mathrm{h}>$ etimológico em contexto medial, que se verifica, por exemplo, nas palavras abstrahir, comprehender, contrahir, exhortar, extrahir. As formas do verbo comprehender, assim como o substantivo comprehensão, surgem trinta e uma vezes no texto e registam sempre $<\mathrm{h}>$ em todas as edições. O mesmo acontece com as formas do verbo exhortar. Porém, no verbo abstrahir, do qual temos ocorrência das formas abstrahir, abstrahido e abstrahindo, na edição $G, \mathrm{o}<\mathrm{h}>$ é eliminado na maior parte das vezes. Por sua vez, nas formas contrahido e contrahimos, do verbo contrahir, já se encontram casos de supressão do $<\mathrm{h}>$ também na edição $F$, se bem que na $G$ são mais frequentes. Esta oscilação que se verifica na grafia destas palavras, sobretudo na última edição, evidencia já uma mudança que se viria a concretizar. ${ }^{7}$

Nos casos em que o $<\mathrm{h}>$ ocorre em palavras que não o têm nas latinas ou em palavras portuguesas, o gramático diz não entender a razão destes usos: "Porêm não havendo $\mathrm{H}$ nas palavras Latinas Unus, Est, Cadere, Salire, Ibi, e sendo puramente Portuguezas Baía, Baú; não sei a razão, porque se escrevem com elle deste modo: Hum, Hé, ${ }^{8}$ Cahir, Sahir, Ahi, Bahia, Bahu'" (ibid., p. 71).

Nesta citação, encontra-se a referência a duas funções do $<\mathrm{h}>$ frequentes na época: as funções distintiva e anti-hiática.

$\mathrm{Na}$ primeira encaixam-se as palavras, que assim se grafavam para se distinguirem de outras: hum (artigo indefinido ou numeral) de $u m$ (vogal nasal); he (verbo) de $e$ (conjunção). ${ }^{9}$ Segundo o gramático, estes casos são exemplos das incoerências da ortografia usual, que não tem em consideração o fenómeno da derivação (cf. ibid., p. 57).

A função anti-hiática do $<\mathrm{h}>$ encontra-se nas palavras cahir, sahir, ahi, bahia, bahú, e serve para evidenciar que as duas vogais em contacto não formam ditongo. Como uma alternativa preferível a este procedimento, a propósito das formas verbais, Soares Barbosa indica o recurso à acentuação, que retiraria as dúvidas:

\footnotetext{
${ }^{7}$ Nas Bases para a Unificação da Ortografia pode ler-se o seguinte: "III. É eliminada a letra $h$ do interior de todos os vocábulos portugueses, com excepção do seu emprêgo, como sinal diacrítico, nas combinações $c h, l h, n h$, com os valores que as seguintes palavras exemplificam, e únicamente para êles: chave, malha, manha" (VIANA, 1911, p. 22).

${ }^{8}$ Repare-se que aqui, para além do uso do $<\mathrm{h}>$, acentua-se esta forma, o que só acontece duas vezes em mais de 1300 ocorrências e se verifica apenas nas três primeiras edições.

${ }^{9}$ A propósito destas duas últimas formas, Verney refere que elas se distinguem facilmente através da acentuação: "O é quando é Verbo, muito bem se-distingue do- $e$ Conjunsam, pondo-lhe emcima um acento. Nem eu poso intender porque razam $e ́$ Verbo, deva escrever-se com $h$, e era, eram \&c. que sam inflexoens do-mesmo Verbo, sem ele" (VERNEY, 1746, p. 23).
} 
Porque, se o $h$, com que ora se escrevem, he para separar as duas vogaes em ordem a não fazerem diphthongo, e mostrar que o $i$ he longo e agudo; muito melhor fazião isto nossos antigos dobrando o $i$, e escrevendo Caiir, Saiir; e nós ainda melhor, accentuando o mesmo $i$ deste modo: Caír, Saír; e tirando o accento, quando faz diphthongo no presente do indicativo e do subjunctivo, como Caio, Caia, Saio, Saia, \&c. (ibid., p. 267).

Desta forma, nestes dois casos enunciados, não sendo o $<\mathrm{h}>$ etimológico, não tem um fundamento lógico. Veja-se, então, o que acontece nos textos das edições.

$\mathrm{Na}$ primeira edição, encontra-se $\mathrm{o}<\mathrm{h}>\mathrm{com}$ a primeira função apontada nas palavras $h e$, hum e hia. Na edição C, a forma verbal he e o artigo indefinido/numeral hum (bem como o seu feminino e plural) deixam de ser grafados $\operatorname{com}<\mathrm{h}>$, passando o primeiro a ser acentuado: é, um, uma, uns, umas. Quanto à forma do verbo $i r$, continua a registar $\mathrm{o}<\mathrm{h}>$ : hia. É a partir da quarta edição que este grafema desaparece por completo destas formas, surgindo elas sempre sem $<\mathrm{h}>$ : é, um, uma, uns, umas, ia. A corroborar estes usos, estão as palavras de Figueiredo Vieira: "Não deve empregar-se o $h$, onde nem a etymologia nem a pronuncia o reclamam; devemos por tanto escrever sem elle é, um, uma, ia, ias \&c" (VIEIRA, op. cit., p. 45).

No que respeita ao uso do $<\mathrm{h}>$ com função anti-hiática, na primeira edição encontramolo em palavras como ahi, cahe, cahem, cahir, cahírão, dahi, sahir, sahissem. No entanto, verifica-se que estas formas convivem dentro do mesmo texto com outras já grafadas $\mathrm{sem}<\mathrm{h}>$ : cae, cair, sae, saem, sair, saindo, entre outras. Mais uma vez, a alteração surge na edição $D$, a partir da qual o $<\mathrm{h}>$ das formas verbais é eliminado, mantendo-se, no entanto, nos advérbios ahi e $d a h i .^{10}$

Outra função reconhecida por Soares Barbosa ao $<\mathrm{h}>$ é como elemento constitutivo dos dígrafos portugueses $<\mathrm{ch}, \mathrm{lh}, \mathrm{nh}>$. O gramático considera que estas prolações devem figurar no alfabeto e "[...] que são humas verdadeiras Consoantes, posto que figuradas com duas Letras [...]” (BARBOSA, op. cit., p. 59). Na verdade, o autor, quando trata das consonâncias da língua portuguesa, em que se incluem estes dígrafos, esclarece que elas correspondem a sons simples, independentemente dos elementos que as compõem:

\footnotetext{
10 Também para este caso o ortógrafo Figueiredo Vieira reconhece o uso do $<\mathrm{h}>$ : "39. ${ }^{\text {a }}$ Emprega-se o $h$ como distinctivo etymologico, ou, em logar da dierisis, para desfazer diphthongos, como na palavra ahi e similhantes" (VIEIRA, op. cit., p. 44).

Mais sistemática é a solução apresentada por Tristão da Cunha Portugal, que, à semelhança do que acontece com a forma verbal é, propõe que nestes advérbios se recorra igualmente ao acento gráfico, evitando assim qualquer possível confusão (cf. PORTUGAL, op. cit., p. 27).
} 
Finalmente cumpre advertir que todas estas Consonancias Portuguezas são sons simples, quer se escrevão com huma letra so, quer com duas, quer com as letras dobradas dos Gregos, e Romanos. Taes são as tres $\mathrm{CH}, \mathrm{LH}, \mathrm{NH}$ (que os nossos antigos Grammaticos chamavão Prolações) [...] (ibid., p. 12).

Para além do gramático considerar estas prolações como grafemas, ainda adverte para o facto delas não serem aspiradas, pois não é por serem constituídas pelo $<$ h $>$ que passam a ter esta característica (cf. ibid., p. 12-13).

Nos textos das edições, são várias as palavras que integram estas prolações puramente portuguesas, das quais apresentamos alguns exemplos: achar, caprichar, chá, coelho, conselho, escolhido, façanhas, ganhar, linha.

A propósito do dígrafo $<$ nh $>$, fica uma advertência para os casos em que se encontra a sequência $<\mathrm{n}+\mathrm{h}>$, em interior de palavra, que não representa um grafema. Isso é visível nas palavras anhomologas, inhabil e resulta da observância do princípio etimológico, verificandose em todas as edições.

Sistematiza-se, de seguida, os dados compulsados acerca dos usos do $<\mathrm{h}>$ nos textos das edições. Por uma questão de organização, apresenta-se a sistematização em duas tabelas distintas, tendo em consideração a ocorrência se verificar em todas as edições ou não.

Tabela 1: O uso do $<\mathrm{h}>$ nas edições (1)

\begin{tabular}{|l|l|l|}
\hline \multirow{2}{*}{$<\mathrm{h}>$} & Sinal de aspiração & ah!, hai!, oh!, ah! ah!, hui! \\
\cline { 2 - 3 } & Etimológico & $\begin{array}{l}\text { habil, habitar, habito, haver, herdar, historia, hombro, honesto, } \\
\text { honra, horror, hospede, homem, humor, hora, horizontaes }\end{array}$ \\
\cline { 2 - 3 } & Dígrafos <ch, lh, nh> & $\begin{array}{l}\text { achar, caprichar, chá, coelho, conselho, escolhido, façanhas, ganhar, } \\
\text { linha }\end{array}$ \\
\hline
\end{tabular}

Tabela 2: O uso do $<\mathrm{h}>$ nas edições (2)

\begin{tabular}{|c|c|c|c|c|c|}
\hline$<\mathrm{h}>$ & Edições $A$ e $B$ & Edição $C$ & Edições $D$ e $E$ & Edição $F$ & Edição $G$ \\
\hline $\begin{array}{l}\text { Sinal } \\
\text { distintivo }\end{array}$ & he, hum, hia & Hia & & & \\
\hline Anti-hiático & $\begin{array}{l}\text { ahi, cahe, } \\
\text { cahem, cahir, } \\
\text { cahírão, dahi, } \\
\text { sahir, sahissem }\end{array}$ & $\begin{array}{l}\text { ahi, cahe, } \\
\text { cahem, cahir, } \\
\text { cahírão, dahi, } \\
\text { sahir, sahissem }\end{array}$ & ahi, dahi & ahi, dahi & ahi, dahi \\
\hline Etimológico & $\begin{array}{l}\text { abstrahir, } \\
\text { abstrahido, } \\
\text { abstrahindo, } \\
\text { comprehender, } \\
\text { contrahido, } \\
\text { contrahimos }\end{array}$ & $\begin{array}{l}\text { abstrahir, } \\
\text { abstrahido, } \\
\text { abstrahindo, } \\
\text { comprehender, } \\
\text { contrahido, } \\
\text { contrahimos }\end{array}$ & $\begin{array}{l}\text { abstrahir, } \\
\text { abstrahido, } \\
\text { abstrahindo, } \\
\text { comprehender, } \\
\text { contrahido, } \\
\text { contrahimos }\end{array}$ & $\begin{array}{l}\text { Começa a ser } \\
\text { suprimido em } \\
\text { formas como: } \\
\text { contrahido, } \\
\text { contrahimos }\end{array}$ & $\begin{array}{l}\frac{\text { Supressão }}{\text { frequente }} \text { em } \\
\text { formas como: } \\
\text { abstrahir, } \\
\text { abstrahido, } \\
\text { abstrahindo, } \\
\text { contrahido, } \\
\text { contrahimos }\end{array}$ \\
\hline
\end{tabular}


Relativamente aos usos do $<\mathrm{h}>$ apresentados, pode-se concluir que são várias as funções que se encontram nas edições e, à exceção de uma, em todas as outras o $<$ h $>$ não tem valor fónico, ou seja, é zerofónico (cf. KEMMLER, 2007, p. 363). ${ }^{11} \mathrm{Na}$ opinião de Filomena Gonçalves,

este é um caso paradigmático de sobrevivência, até hoje, de unidades gráficas que são mero reflexo da historicidade da língua na sua vertente escrita, sendo que esta não só representa a vertente oral como lhe serve de memória, razão por que até ao nosso século houve ambiguidade entre os dois planos, e a consequente sobreposição (GONÇALVES, 2003, p. 511).

Seguindo os princípios do autor, este grafema regista-se nos textos com a função de aspiração, como elemento das prolações $<\mathrm{ch}, \mathrm{lh}, \mathrm{nh}>\mathrm{e}$ como marca etimológica. No que toca a esta última função, nas palavras em que o $<\mathrm{h}>$ surge em contexto medial, particularmente nos verbos abstrahir e contrahir, começa-se a assistir a uma tendência de eliminação a partir da edição $F$, que se torna mais frequente na edição $G$.

Verifica-se, ainda, a ocorrência do $<\mathrm{h}>$ com as funções distintiva e anti-hiática, usos que não são etimológicos e que o gramático diz não terem qualquer razão, a não ser as arbitrariedades do uso. Quanto à função distintiva, ela só se verifica nas três primeiras edições, sendo que inclusivamente na terceira $\mathrm{o}<\mathrm{h}>$ já só se regista no verbo ir. Finalmente, $\mathrm{o}<\mathrm{h}>$ antihiático encontra-se nas edições $A, B$ e $C$ em formas verbais e nos advérbios ahi e dahi e, a partir da edição $D$, passa a registar-se apenas nos dois advérbios mencionados.

\subsubsection{O uso do $<\mathrm{h}>$ nos dígrafos gregos}

O papel do $<\mathrm{h}>$ não se esgota, porém, nas funções acima indicadas. Ele é também parte integrante dos dígrafos gregos $<\mathrm{ch}$, ph, th, rh>, cujo uso se generalizou com a chegada do Renascimento e consequente aproximação do português às línguas clássicas.

Na Grammatica Philosophica, a abordagem a estes dígrafos é feita no capítulo dedicado às ortografias etimológica e usual, no qual Soares Barbosa estabelece uma regra única:

Toda a palavra Portugueza, que for dirivada ou da Lingua Grega, ou da Latina, deve conservar na escriptura os caracteres da sua origem, que se poderem representar pelos do nosso Alphabeto, e forem compativeis com a nossa pronunciação. Mas o uso faz nesta regra todas as excepções, que quer (BARBOSA, op. cit., p. 68).

\footnotetext{
${ }^{11}$ Em 1868, Adolfo Coelho já destacava o facto de $\mathrm{o}<\mathrm{h}>$ não ter qualquer valor fónico em português: "O caracter $h$ não designa em o nosso systema phonographico a aspiração que exprimia no systema phonographico latino: a spirante guttural tornou-se inteiramente muda no portuguez" (COELHO, 1868, p. 82).
} 
Através da exposição desta regra, o gramático dá-nos conta de que, segundo a ortografia etimológica, dever-se-iam escrever todas as palavras derivadas do grego e do latim de acordo com a sua etimologia, recorrendo para tal aos carateres do nosso alfabeto. Assim, para representar os quatro sons aspirados das letras gregas $\langle\theta\rangle,\langle\cdot\rangle,\langle\varphi\rangle$ e $\langle\chi\rangle$ encontramos no português os dígrafos $<$ th $>,<\mathrm{rh}>,<\mathrm{ph}>\mathrm{e}<\mathrm{ch}>$. Atente-se, no entanto, na última frase da citação, que nos indica que, apesar de esta ser a regra, o uso encarrega-se de introduzir muitas alterações, como veremos em cada um dos casos.

No que respeita ao dígrafo $<\mathrm{ch}>$, o gramático proscreve o seu uso e justifica esta opção remetendo para a regra citada e argumentando que esta prolação já tem uma função na língua portuguesa. Posto isto, não pode ser empregue em representação do $\langle\chi\rangle$ sem que se gere equívoco:

Disse na Regra: Que se poderem representar pelos caracteres do nosso Alphabeto: porque algumas não se podem; ou por não termos nelle letra propria para isto, como o K antes de e, e i, que substituimos com a Prolação Latina QU: ou por termos ja preoccupado para alguma das nossas consonancias proprias as Letras que competirião ás Gregas e Latinas, como o $\mathrm{CH}$, que servindo-nos para figurar a nossa chiante muda, como em Chá, ja a não podemos empregar sem equivoco em Archãjo, Architecto \&c. (ibid., p. $69)$.

Esta posição é criticada por Feijó (cf. FEIJÓ, op. cit., p. 54), para quem não se justifica eliminar $\mathrm{o}<\mathrm{ch}>$ só porque se pode tornar dúbia a significação das palavras ou porque se tornam incompreensíveis para o vulgo ignorante. ${ }^{12}$

Para substituir este dígrafo, Soares Barbosa aponta o uso de $<\mathrm{c}>$ antes de $<\mathrm{a}>$ e de $<\mathrm{qu}>$ antes de $<\mathrm{i}>$ :

Não usamos ja de $\mathrm{CH}$ aspirado pelas razões, que apontei no principio do Capitulo. Em lugar delle pomos $\mathrm{C}$ simples antes de a, escrevendo Arcanjo, Monarca; e QU antes de i, escrevendo Arquitecto, Monarquia, e não Archanjo, Monarcha, Architecto, Monarchia, como antes se escrevia (BARBOSA, op. cit., p. 70-71).

\footnotetext{
${ }^{12} \mathrm{O}$ ortógrafo, para este dígrafo, propõe uma solução que combina uso e etimologia:

"Em nenhuma palavra portugueza póde haver $C$ aspirado com $H$ no som de $Q$; mas ou haõ de ser tiradas dos latinos, ou dos Gregos; e ou sejaõ de huns, ou de outros, se as traduzimos ao nosso uso, naõ necessitaõ de $H$ para a sua Orthografia, e pronunciaçaõ portugueza; porque o nosso $C$ tem a consonancia de $Q$, antes das vogaes $a, o, u$, quando se naõ escreve plicado; como v. g. Caro, Corôa, Cura, \&c. Mas se as traduzimos ao uso latino, ou alatinado, sem as extrahir da sua pronunciaçaõ, e significação latina, entaõ precisamente se haõ de escrever como os latinos as escrevem, por naõ fazermos humas palavras, que nem seraõ latinas, nem portuguezas; e por naõ lhes tirarmos as letras, que nos mostraõ a sua origem, para sabermos o que significaõ (FEIJÓ, op. cit., p. 55).”
} 
Apesar destas reflexões do gramático, nos textos das edições encontra-se ainda a utilização da grafia <ch> para representar o som [k], nomeadamente nas palavras Christo, Chrysippo, echo, epochas, eschola, inchoativa, mechanico, patriarcha, psychologicas. No entanto, verifica-se que esta grafia convive com a outra, como demonstra a ocorrência dos pares eschola / escola, mechanico / mecanicos. A oscilação na grafia destes pares vai-se manter até à quinta edição, a partir da qual são uniformizados, mas com opções diferentes: para o primeiro dos pares a opção passa pela simplificação, adotando-se a forma escola; relativamente ao segundo par, vão-se alterar todos os casos para a forma mechanico, mantendo-se, portanto, o dígrafo.

Assim, ainda que o autor refira que já não se usa o $<$ ch $>$ aspirado, este encontra-se na grafia de algumas palavras derivadas do grego desde a primeira até à última edição. ${ }^{13}$

Relativamente ao dígrafo $\langle$ ph $>$, ele é usado para representar o $\langle\varphi>$ grego e, segundo o autor, de todos, este é o dígrafo que o uso mais tem substituído:

Das consoantes Gregas aspiradas, a que o uso está mais propenso a largar da nossa Orthographia he o $\mathrm{PH}$, que elle sem rebuço ja escreve com $\mathrm{F}$ em Filosofia, Fysica, Metafysica, Profeta, Triumfo, e podia escrever da mesma maneira Antiphona, Aphorismo, Blasphemo, Phantasma, Philippe, Camphora, Diphthongo, Phebo, Phaetonte, Alphabeto \&c. (ibid., p. 70).

As palavras do gramático refletem uma certa flexibilidade, pois refere que usualmente já se escrevem várias palavras com $<\mathrm{f}>$ em substituição do $<\mathrm{ph}>$ e ainda se podiam escrever mais. ${ }^{14}$ Dessa ocorrência dá também conta Caetano de Lima: "Quanto a PH naõ usa tanto de Aspiraçaõ; e muitas vezes escreve: Anfiteatro, Blasfemia, Filippe, Filosofo, Proféta, Triunfo" (LIMA, 1736, p. 90).

A propósito deste dígrafo, Beauzée questiona por que razão se multiplica a representação de um mesmo som e exemplifica com o caso dos italianos, que não deixam de ser bons

\footnotetext{
${ }^{13}$ Durante o século XIX, os ortógrafos continuaram a propor esta grafia e a elencar as listas de palavras que com

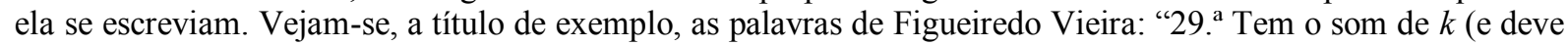
empregar-se) nas palavras derivadas do Grego, e que n-essa lingua tinham a lettra $\chi$ [...]" (VIEIRA, op. cit., p. 40).

${ }^{14}$ Feijó, embora proponha o uso do <ph>, e até o queira introduzir no nosso abecedário (cf. FEIJÓ, op. cit., p. 60), facto que chega a ser concretizado por Monte Carmelo (cf. CARMELO, 1767, p. 135), também evidencia alguma flexibilidade, nomeadamente nos nomes apelativos:

"116 O que me parece he, que na Orthografia das palavras Gregas, que saõ nomes proprios, naõ se mude o $P h$ em $F$, para as naõ fazermos improprias, e tirar-lhes o distinctivo de que saõ Gregas. Nas appellativas, quem usar de $P h$, escreverá sem erro, e por analogia; quem escrever $\operatorname{com} F$, fará a palavra Grega aportuguezada; e naõ deixará de escrever bem; porque sempre fica a mesma pronunciaçaõ (FEIJÓ, op. cit., p. 61).”
} 
etimologistas por terem banido o $<$ ph $>$ da sua língua (cf. BEAUZÉE, 1767, I, p. 192). No caso português, em meados do século XIX, ainda ouvimos vozes bastante desfavoráveis e críticas à eliminação deste elemento, de que é exemplo Figueiredo Vieira:

[...] de tal sorte se hão confundido em Portugal os principios orthographicos, que foi sustentado por homens eruditos e por corporações respeitaveis, que o ph devia ser banido de nossa escripta! Queriam elles que se escrevesse anfitheatro, typografia \&c.; e vinham assim a ter metade da palavra escripta segundo a orthographia etymologica, e a outra metade segundo a philosophica. Que sublime concepção!! (VIEIRA, op. cit., p. 51)

No tocante à ocorrência deste dígrafo nos textos das edições, constata-se que ele surge em palavras como anastrophes, bucephalo, cacophonia, diphthongo, elephante, orthographia, paragraphos, phenomenos, phrases, entre outras. Note-se que a palavra phrases só tem uma ocorrência com $<$ ph $>$ entre mais de sessenta e a partir da quarta edição também esta é alterada para frases.

Fizemos, ainda, uma pesquisa pelos exemplos que o autor apresenta como usualmente escritos com $<\mathrm{f}>$ (filosofia, fysica, metafysica, profeta, triumfo) e todos eles, com exceção de triumfo, do qual não há mais nenhuma ocorrêneia, se encontram grafados em outros passos com $<$ ph $>$ (philosophia, physica, metaphysica, propheta), o que reforça a ideia de variação existente, bem como a força da etimologia.

O mesmo se passa com o dígrafo $<$ th $>$, para o qual o gramático diz encontrar palavras em que este se usa e em que se elimina:

O TH aspirado, ainda que o não seja por nós, conserva-se na escriptura das palavras, que o tem na Lingua Grega, como Antipathia, Orthodoxo, Timotheo, Thesouro, Theatro, Thuribolo, Throno, Theologia, Mathematica \&c. Comtudo não se repara que alguns escrevão Asma, Catarina, Cantaro, Citara, Catolico, Tio, que na sua origem tem o th aspirado (BARBOSA, op. cit., p. 70).

Nas edições, o <th> surge nas palavras Athenas, author, authorizado, epenthese, labirintho, methodo, orthoepia, parenthese, pathetico, theoria, thesouro, entre outras.

Das palavras que o autor apresenta como exemplos de formas que alguns usam $\mathrm{sem}<\mathrm{th}>$, nos textos, há ocorrências de Catharina e catholica, que surgem representadas com o dígrafo. 
As formas author e authorizado convivem nas três primeiras edições com auctor ${ }^{15} \mathrm{e}$ auctorizado, sendo estas últimas as maioritárias e etimológicas. Estes erros eram bastante comuns, segundo o que dá conta Tristão da Cunha Portugal:

$6^{\text {a }}$ Assim como por coherencia escrevemos com $h$ as palavras que o tem no latim, como fica dicto na regra $1^{\mathrm{a}}$, deve elle ser excluido d'aquellas outras que um mero uso irreflectido costuma dar-lhe, como em auctor, auctoria, ancora, têor, conteúdo, até, derivadas das latinas auctor, ancora, tenor, contentum, etc (PORTUGAL, op. cit., p. 28).

$\mathrm{Na}$ verdade, seria pouco provável que Soares Barbosa escrevesse a palavra auctor com $<$ th $>$, pois ele próprio adverte para casos em que o uso deste dígrafo contraria a etimologia, nomeadamente nas palavras teúdo e conteúdo: "Escrever Theúdo, Contheúdo he contra a Etymologia" (BARBOSA, op. cit., p. 70).

Dos quatro dígrafos, resta apenas o $<\mathrm{rh}>,{ }^{16}$ usado no grego para representar o 'rô' aspirado. Como o próprio autor salienta, ele é raro em grego, e muito mais em português: "O RH aspirado he mais raro nas palavras Gregas, e muito mais nas poucas, que com elle passárão ao Portuguez como Rhetorica e não Rethorica, como alguns escrevem, Rheumatismo, Catarrho, que ja muitos escrevem Reumatismo, Catarro" (ibid., p. 70).

Assim, para além dos exemplos já apresentados na citação, apenas se encontram nos textos mais três palavras grafadas com $<\mathrm{rh}>$ : arrhas, pyrrhonicos e rhythmo, não se registando qualquer variação.

Segue-se a sistematização dos usos destes grupos greco-latinos nas edições.

Tabela 3: $\mathrm{O}$ uso do $<\mathrm{h}>$ nos dígrafos gregos nas edições

\begin{tabular}{|c|l|}
\hline & \multicolumn{1}{|c|}{ Edições $A, B, C, D, E, F, G$} \\
\hline Dígrafo $<\mathrm{ch}>$ & $\begin{array}{l}\text { Christo, Chrysippo, echo, epochas, inchoativa, mechanico, } \\
\text { patriarcha, psychologicas }\end{array}$ \\
\hline Dígrafo $<\mathrm{ph}>$ & $\begin{array}{l}\text { anastrophes, bucephalo, cacophonia, diphthongo, elephante, } \\
\text { metaphysica, orthographia, paragraphos, phenomenos, philosophia, } \\
\text { phrases }\end{array}$ \\
\hline Dígrafo $<\mathrm{th}>$ & $\begin{array}{l}\text { Athenas, author, authorizado, Catharina, diphthongo, epenthese, } \\
\text { labirintho, methodo, orthoepia, parenthese, pathetico, theoria, } \\
\text { thesouro }\end{array}$ \\
\hline Dígrafo $<\mathrm{rh}>$ & arrhas, pyrrhonicos, rhythmo \\
\hline
\end{tabular}

\footnotetext{
15 Para esta palavra, também encontramos um exemplo de grafia sem $<\mathrm{c}>$ : autor, que é alterada para auctor, a partir da quarta edição.

${ }^{16}$ Quando faz referência aos diferentes contextos em que ocorre a letra $<\mathrm{r}>$, Feijó não apresenta este dígrafo, porém na terceira parte da sua Orthographia elenca algumas palavras que se escrevem com $<\mathrm{rh}>$.
} 
Com efeito, da análise das ocorrências destes dígrafos verifica-se que, ainda que Soares Barbosa refira que muitas destas palavras já se escreviam com $<\mathrm{c}$, qu, f, t, $\mathrm{r}>$, o que se constata é que os dígrafos que representam as consoantes aspiradas gregas ainda se mantêm nas edições, inclusivamente na última, que data de $1881 .{ }^{17}$ Esta oscilação de grafias evidencia o cruzamento do sistema etimológico com o sistema da pronunciação, originando um sistema misto.

\subsection{Uso do apóstrofo}

O termo apóstrofo, oriundo do grego $₫$ pÒstrofoj, designava um sinal de elisão (cf. BAILLY, s/d, p. 245). Soares Barbosa insere-o no segundo parágrafo dedicado aos sinais de pontuação e denomina-o viraccento ou apostrophe.

$\mathrm{Na}$ definição que apresenta, o autor descreve a figura e a função deste sinal:

O Viraccento, ou Apostophe [sic!] (') he huma virgula, não ja posta em baixo para signal de pausa, mas no alto de huma consoante para mostrar que se lhe supprimio a sua vogal final antes de outra inicial da palavra seguinte, com a qual vogal se ajunta a mesma consoante, pronunciando-se juntas as duas palavras, como Minh'alma (BARBOSA, op. cit., p. 94).

Assim, este sinal, para o gramático, tem a função de assinalar elisões ou synalephas de uma vogal ou consoante. No entanto, verifica-se que o autor não lhe confere muita relevância, prescrevendo a contração direta das formas mais frequentes, o que se deve ao facto de distinguir claramente o plano fónico do plano gráfico:

Estes $V$ iraccentos são pouco usados na escriptura da nossa prosa, não obstante serem frequentes estas elisões, ou synalephas, principalmente nas preposições De, Em, Per, Por, Com antes do artigo, e dos demonstrativos, como do, da, dos, das, delle, daquelle \&c. em lugar de d'o, d'a, d'os, d'as, d'elle, d'aquelle: e do mesmo modo no, na, nos, nas, neste, nesse, naquelle, pelo, pela, polo, pola, em lugar de n'o, n'a, n'os, n'as, n'este, n'esse, n'aquelle, pel'o, pel'a, pol'o, pol'a (ibid., p. 94).

Desta forma, ainda que reconheça estas elisões, que produzem uma maior rapidez na oralidade, o gramático dispensa o uso do apóstrofo, pois na escrita usual "[...] as duas palavras se costumão escrever junctas em huma, [...]" (ibid., p. 24). Além disso, o autor alega ainda razões de natureza estética para o parco uso que se faz deste sinal na escrita, circunscrevendoo ao verso:

\footnotetext{
${ }^{17}$ Quatro anos depois, Gonçalves Viana e Vasconcelos Abreu propõem que sejam "[...] banidos da escrita os símbolos gráficos sem valor de fonema próprio. São eles $t h, p h, c h$, respectivamente por $t, f, q(u), c(a, o, u), c[\ldots]$ ” (VIANA E ABREU, 1885, p. 9).
} 
Como estas preposições com o artigo, e demonstrativos occorrem a cada passo na escriptura; o uso do viraccento em todas, alêm de impedir a facilidade da escriptura cursiva, retalha muito a sua continuação, e desfigura a sua belleza; e por isso a Orthographia presente o tem desterrado da prosa, e largado ao verso; onde so se costuma tambem escrever com elle a preposição com tirando-lhe o $m$ deste modo Co'elle, Co'esse, Co'este \&c. (ibid., p. 94).

De acordo com o gramático, o apóstrofo também pode ser usado para assinalar a elisão da vogal das enclíticas $m e$, te, lhe, quando se lhe segue outra enclítica, ${ }^{18}$ como por exemplo, tirar-m'-o, tirar-t'-as, tirar-lh'-o, mas a escrita usual costuma unir as duas enclíticas em uma só (cf. ibid., p. 94).

No que respeita ao uso do apóstrofo nas edições, podem-se dividir os textos em dois grupos: de um lado encontram-se as edições $A, B$ e $C$; e de outro as edições $D, E, F$ e $G$.

Nas três primeiras edições, o apóstrofo ocorre sobretudo em expressões em que se assinala a contração da preposição com um nome, como em caixa d'ouro, dotes d'alma, ning'omem, venho d'Inglaterra, vista d'olhos. Pode também encontrar-se este sinal quando se junta um determinante demonstrativo ao indefinido outro, como em est'outro, ess'outra, aquell'outra, no entanto, paralelamente a estas formas ocorrem outras grafadas sem apóstrofo: estoutro, essoutra, aquelloutra. ${ }^{19}$

Relativamente às formas em que se contraem as preposições de ou $\mathrm{em}^{20} \mathrm{com}$ o artigo e com os demonstrativos ou as preposições per e por com o artigo, a tendência nas três primeiras edições é seguir os princípios que Soares Barbosa propõe, isto é, contrair as duas formas, dispensando o uso do apóstrofo. Não significa isto, porém, que não se registem formas destas em que se recorre ao apóstrofo: elas ocorrem, todavia, residualmente. Só para termos uma ideia, existem nove ocorrências da forma d'o para mil e quatrocentas da forma $d o$.

\footnotetext{
18 "Muitas vezes com hum mesmo verbo de significação activa e ao mesmo tempo relativa concorrem os dous Complementos, objectivo e terminativo, exprimidos por dous Pessoaes, e então se costumão encorporar hum n'o outro, elidindo-se a vogal ou consoante do primeiro, como m'o, nol'o, v'olo, lh'o, lh'a, lh'os, lh'as em lugar de me-o, nos-o, vos-o, the-o, ou lhes-o, lhe-a, lhe-os, lhe-as, sobre o que se pode ver o que fica dicto na Orthoepia Cap. VII" (BARBOSA, 1822, p. 157).

${ }^{19}$ Estas são, aliás, as formas que ocorrem na taboa que sintetiza as variações que os demonstrativos podem assumir.

${ }^{20}$ Soares Barbosa entende que, quando a preposição em se contrai com o artigo ou com os demonstrativos, existe, como acontece com a preposição de, uma elisão da vogal, uma vez que a preposição sofre uma metátese, trocando $\mathrm{o}<\mathrm{m}>$ em $<$ n $>$ e elidindo o $<$ e $>$ (cf. ibid., p. 25).
} 
Quando à preposição de se juntam as palavras alli, antes, aqui, onde, novamente a tendência é que o viraccento não ocorra: dalli, dantes, daqui, donde, muito embora também se possam encontrar formas apostrofadas, mas, tal como no caso anterior, em menor escala. ${ }^{21}$

Nas quatro últimas edições, o uso do apóstrofo, para além de ocorrer nas expressões indicadas acima (caixa d'ouro, dotes d'alma, ning'omem, venho d'Inglaterra, vista d'olhos), também se verifica sempre que às preposições de e em se segue um determinante, como em d'elle, d'aquellas, d'isso, d'isto, n'aquelle, n'este, n'isso, n'isto, ${ }^{22}$ e quando à̀ preposição de se juntam as palavras alli, antes, aqui, onde, registando-se d'alli, d'antes, d'aqui, d'onde.

Assim, nas edições $D, E, F$ e $G$, assiste-se a um incremento do uso do apóstrofo, mesmo em situações que Soares Barbosa aponta como já consagradas pelo uso, o que pode ser uma consequência da imitação da ortografia francesa, como refere e critica Gonçalves Viana:

A meu ver, o uso do apóstrofo só é conveniente limitando-se a formas pouco triviais, e sobretudo se se aplicar únicamente a indicar a supressão de letras, e não a outros fins, como erróneamente e por imitação da ortografia francesa se faz na actualidade, por exemplo quando se emprega nos vocábulos n'este, n'um e nas formas douvo'los, davam-n'o, d'armada, por da armada, etc (VIANA, 1904, p. 203-204). ${ }^{23}$

Resumem-se, de seguida, os usos do apóstrofo nas edições, tendo em conta os princípios advogados por Soares Barbosa.

Tabela 4: Uso do apóstrofo nas edições

\begin{tabular}{|l|l|l|}
\hline & \multicolumn{1}{|c|}{ Edições $A, B, C$} & \multicolumn{1}{c|}{ Edições $D, E, F, G$} \\
\hline $\begin{array}{l}\text { Preposição seguida de } \\
\text { nome }\end{array}$ & $\begin{array}{l}\text { caixa d'ouro, dotes d'alma, ning'omem, } \\
\text { venho d'Inglaterra, vista d'olhos }\end{array}$ & $\begin{array}{l}\text { caixa d'ouro, dotes d'alma, ning'omem, } \\
\text { venho d'Inglaterra, vista d'olhos }\end{array}$ \\
\hline $\begin{array}{l}\text { Preposição seguida de } \\
\text { pronome ou advérbio }\end{array}$ & $\begin{array}{l}\text { Pode ocorrer, mas residualmente. } \\
\text { d'elle, d'aquellas, d'isso, d'isto, n'aquelle, } \\
\text { n'este, n'isso, n'isto, d'alli, d'aqui, d'onde }\end{array}$ \\
\hline
\end{tabular}

Desta forma, pode-se concluir que, nas três primeiras edições, embora não exista total uniformidade, a tendência é a eliminação do apóstrofo nas formas de uso frequente, ao passo que nas quatro últimas edições o uso do apóstrofo é muito mais significativo, registando-se inclusive em formas que Soares Barbosa considerava serem já vulgarmente usadas sem ele.

\footnotetext{
${ }^{21}$ A título de exemplo, da forma daqui há sessenta e três ocorrências para apenas três da forma apostrofada $d$ 'aqui. ${ }^{22}$ Figueiredo Vieira critica o uso do apóstrofo nas formas contraídas com a preposição em, uma vez que neste caso não é elidida qualquer vogal: "É erro pôr apostropho nas palavras n-este, n-aquelle \&c., por não haver n-ellas suppressão de vogal" (VIEIRA, op. cit., p. 69-70).

${ }^{23}$ Posto isto, a proposta do autor é a seguinte: “Assim, devemos escrever sem apóstrofo neste, dêste, dahi (ou daí), como já escrevemos no, do, donde; semelhantemente no-lo, vo-lo, lho (= lhe-o, lhes-o) mo, to, isto quer haja, quer não, hífen" (VIANA, 1904, p. 204).
} 


\section{Conclusão}

Durante os séculos XVIII e XIX, a questão ortográfica foi amplamente discutida e a necessidade de fixação de uma única escrita normativa é visível no incremento da produção de tratados ortográficos, que se sucediam uns após outros, sem, no entanto, se chegar a uma decisão 'definitiva'.

Esta é, também, a conclusão que se-nos impõe da análise da teorização ortográfica de Jerónimo Soares Barbosa, confrontada com as propostas de outros autores, bem como da grafia adotada nas sete edições da Grammatica Philosophica.

Neste período, há um constante confronto entre duas forças distintas, embora complementares: a fonética e a etimologia. Na Grammatica Philosophica, como vimos, Soares Barbosa indica regras próprias para cada um destes sistemas ortográficos, informando o leitor das características inerentes a cada um e dando-lhe a possibilidade de escolha. Pode-se concluir que sobressai das palavras do gramático um pendor descritivo, em que não se encontra o habitual discurso impositivo das gramáticas normativas e em que se evidencia o papel ativo do falante na construção da escrita.

\section{Referências Bibliográficas}

AZEVEDO, R. C. d'. Os Soares Barbosa - Ansianenses Ilustres. Leiria: Textiverso, colecção Tempos \& Vidas - 20, 2012.

BAILLY, A. Dictionnaire grec-français. Édition revue par L. Séchan et P. Chantraine. Paris: Hachette, s/d.

[BARBOSA, J. S.]. Eschola Popular das Primeiras Letras dividida em quatro partes. Parte Terceira. Da Calligraphia, E Orthographia, ou arte de escrever bem e certo a lingua portugueza. Coimbra: Na Real Imprensa da Universidade, 1796c.

BARBOSA, J. S. Grammatica Philosophica da Lingua Portugueza ou principios da grammatica geral applicados á nossa linguagem. Lisboa: Typographia da Academia das Sciencias, ${ }^{1} 1822$.

BARBOSA, J. S. Grammatica Philosophica da Lingua Portugueza ou principios da grammatica geral applicados á nossa linguagem. Lisboa: $\mathrm{Na}$ Typographia da Mesma Academia, ${ }^{2} 1830$.

BARbOSA, J. S.. Grammatica Philosophica da Lingua Portugueza ou principios da grammatica geral applicados á nossa linguagem. Lisboa: Typographia da Academia, ${ }^{3} 1862$. 
BARBOSA, J. S.. Grammatica Philosophica da Lingua Portugueza ou principios da grammatica geral applicados á nossa linguagem. Lisboa: Typographia da Academia Real das Sciencias, ${ }^{4} 1866$.

BARBOSA, J. S. Grammatica Philosophica da Lingua Portugueza ou principios da grammatica geral applicados á nossa linguagem. Lisboa: Typographia da Academia Real das Sciencias, ${ }^{5} 1871$.

BARBOSA, J. S. Grammatica Philosophica da Lingua Portugueza ou principios da grammatica geral applicados á nossa linguagem. Lisboa: Typographia da Academia Real das Sciencias, ${ }^{6} 1875$.

BARBOSA, J. S. Grammatica Philosophica da Lingua Portugueza ou principios da grammatica geral applicados á nossa linguagem. Lisboa: Typographia da Academia Real das Sciencias, ${ }^{7} 1881$.

BARBOSA, J. S. Gramática Filosófica da Língua Portuguesa (1822). Edição fac-similada, comentário e notas de Amadeu Torres. Lisboa: Academia das Ciências de Lisboa, ${ }^{8} 2004$.

BARRETO, J. F. Ortografia da lingua portugueza per Joam Franco Barreto, offerecida ao $S^{\text {or }}$ Francisco de Mello; Filho primogenito do Dor Garcia de Mello, do Conselho de S.A. \& seu Monteyro mór. Lisboa: Na Officina de Ioam da Costa, 1671.

BEAUZÉE, N. Grammaire Générale, ou Exposition raisonée des éléments necessaires du langage, pour servir de fondement à l'étude de toutes les langues. Paris: De l'imprimerie de J. Barbou, 1767.

COElho, F. A. A Lingua Portugueza. Phonologia, Etymologia, Morphologia e Syntaxe. Coimbra: Imprensa da Universidade, 1868.

FEIJÓ, J. de M. M. Orthographia, ou arte de escrever, e pronunciar com acerto a lingua portugueza para uso do excellentissimo duque de Lafoens. Lisboa: na Regia Officina Typografica, ${ }^{3} 1781$

GONÇALVES, M. F. Madureira Feijó: ortografista do século XVIII; para uma história da ortografia portuguesa. Lisboa: Instituto de Cultura e Língua Portuguesa. Ministério da Educação (Identidade Série Língua Portuguesa), 1992.

GONÇALVES, M. F. As ideias ortográficas em Portugal. De Madureira Feijó a Gonçalves Viana (1734-1911). Braga: Fundação Calouste Gulbenkian, 2003.

GUSMÃO, [F.] [A.] R[.] de. Apontamentos para a continuação da Bibliotheca Lusitana. I. Jeronymo Soares Barbosa. O Instituto. Jornal Scientifico e Litterario, Coimbra, 22 (Fevereiro 15 - 1857), vol. V, p. 259-262, 1857.

KEMMLER, R. Para uma história da ortografia portuguesa: o texto metaortográfico e a sua periodização do século XVI até à reforma ortográfica de 1911. Lusorama Nr. 47-48 (Oktober 2001), p. 128-319, 2001. 
KEMMLER, R. A Academia Orthográfica Portugueza na Lisboa do Século das Luzes. Vida, obras e actividades de João Pinheiro Freire da Cunha (1738-1811). Frankfurt am Main: Domus Editoria Europaea, 2007.

KEMMLER, R. A evolução das ideias ortográficas de Jerónimo Soares Barbosa: da Escola Popular (1796) à Grammatica Philosophica da Lingua Portugueza (1822). In: COSTA, A. I FLORES, C. / ALEXANDRE, N. (org.), XXVII Encontro Nacional da Associação Portuguesa de Linguística: Textos Selecionados, CD-ROM, p. 297-318, 2012a.

KEMMLER, R. Diccionario Bibliographico Portuguez (1858-1958): contributos e limitações para a disciplina da historiografia linguística portuguesa. In: PETROV, P. / SOUSA, P. Q. de / SAMARTIM, R. L-I. / FEIJO, E. J. T. (eds.): Avanços em Ciências da Linguagem. Santiago de Compostela: Associação Internacional de Lusitanistas, Através editora, p. 93-116, 2012b.

L[EAL, J. da S.] M[.]. Jornal do Commercio n. ${ }^{\circ}$ 1874". In: BARBOSA, J. S. Analyse dos Lusiadas de Luiz de Camões. Coimbra: Imprensa da Universidade, p. 3, 1859.

LIMA, L. C. de. Orthographia da Lingua Portugueza. Lisboa Occidental: Na Officina de Antonio Isidoro da Fonseca, 1736.

MONTE CARMELO, Frei L. do. Compendio de Orthografia. Lisboa: Na Officina de Antonio Rodrigues Galhardo, 1767.

PORTUGAL, T. da C.. Orthographia da Lingoa Portugueza. Pariz: V ${ }^{a}$ J. -P. Aillaud, Monlon e Ca , Livreiros de Suas Magestades O Imperador do Brasil e el-Rei de Portugal, ${ }^{2} 1856$.

SILVA, I. F. da. Diccionario Bibliographico Portuguez. Volume III. Lisboa: na Imprensa Nacional, 1859.

[VERNEY, L. A.]. Verdadeiro Metodo de Estudar. Tomo Primeiro. Valensa: Na oficina de Antonio Balle, ${ }^{2} 1746$.

VIANA, A. R. G., e ABREU, G. de V. Bases da Ortografia Portuguesa. Lisboa: Imprensa Nacional, 1885.

VIANA, A. R. G. Ortografia Nacional. Sistematização e Uniformização Sistemática das Ortografias Portuguesas. Lisboa: Livraria Editora Viuva Tavares Cardoso, 1904.

VIANA, A. R. G. (Relator). Bases para a Unificação da Ortografia. Lisboa: Imprensa Nacional, 1911.

VIEIRA, C. A. de F. Ensaio sobre a Orthographia Portugueza. Porto: Typographia Commercial, 1844.

Artigo recebido em: 28.02.2014

Artigo aprovado em: 17.06.2014 